\title{
Engineering and humanitarian intervention: learning from failure
}

\author{
Adeela Arshad-Ayaz (D, M. Ayaz Naseem and Dania Mohamad
}

\begin{abstract}
In this paper, we challenge the belief that failure is necessarily a bad outcome. Instead, we argue that failurespecifically articulated as productive failure-should rather be seen as an educational moment and learning opportunity. Furthermore, we examine the field of humanitarian engineering to argue that the failures of various humanitarian engineering interventions are not necessarily because of flaws in the design process but due to the dominance of the mainstream development discourse, which obscures the importance of local contexts, knowledge, and wisdom. We ground the discussion in the broader context of contemporary development discourses and examine some examples of the failure of engineering and humanitarian assistance/development projects that can be converted into "productive failures" and used as learning opportunities.
\end{abstract}

Keywords: Development, Humanitarian engineering, Humanitarian interventions, Critical socio-technical knowledge

For the past few years, we (first two authors) have engaged in teaching a summer course on humanitarian engineering to an international group of engineering students. Our interactions and conversations with a diverse international group of engineering students have helped us unpack the worldview that dominates their ontological assumptions about the nature of their work and their professional relationship to the world. As social scientists and peace educators with decades of firsthand experience in international development, we found many assumptions held by these bright minds problematic on account of being excessively focused on the techno-economic aspects of humanitarian engineering projects while lacking criticality needed to examine intersectionalities between the techno-economic, sociocultural, political, and environmental elements. Before we proceed, we would like to clarify that our arguments should not read as charges against engineering students. Students should not be held accountable for the gaps in curricular, evaluative, and pedagogical practices. Such omissions fall in the realm of educational policymaking

\footnotetext{
*Correspondence: adeela.ayaz@gmail.com

Department of Education, Concordia University, Montreal, Canada
}

and have close ties with the global politics of power domination.

In this paper, we challenge the belief that failure is necessarily a bad outcome. Instead, we posit that failure should rather be seen as an educational moment and learning opportunity. Specifically, we examine the field of humanitarian engineering to argue that the failures of various humanitarian engineering interventions are not necessarily because of flaws in the design process but due to the dominance of the mainstream development discourse, which obscures the importance of local contexts, knowledge, and wisdom. The discussion in this paper is organized into five sections. In the first section, we present a brief overview of the field of humanitarian engineering and some of the major assumptions that undergird the field. In the second section, we discuss the notions of unproductive success and productive failure to unpack the idea of failure as a learning opportunity. In the third section, we examine contemporary development discourses, their significant assumptions, and some of the fallacies that have been the cause of the failure or underperformance of several development projects. In the fourth section, we use this conceptual framework to examine some examples of the failure of engineering and development projects that can be converted into
Springer Open
(ㅇ The Author(s). 2020 Open Access This article is licensed under a Creative Commons Attribution 4.0 International License, which permits use, sharing, adaptation, distribution and reproduction in any medium or format, as long as you give appropriate credit to the original author(s) and the source, provide a link to the Creative Commons licence, and indicate if changes were made. The images or other third party material in this article are included in the article's Creative Commons licence, unless indicated otherwise in a credit line to the material. If material is not included in the article's Creative Commons licence and your intended use is not permitted by statutory regulation or exceeds the permitted use, you will need to obtain permission directly from the copyright holder. To view a copy of this licence, visit http://creativecommons.org/licenses/by/4.0/. 
"productive failures" and used as learning opportunities. In the final section, we present our concluding thoughts.

\section{Humanitarian engineering}

According to Mazzurco and Daniel (2020), "Humanitarian engineering (HE) is an engineering specialization that focuses on the design of products, systems, or services to support the sustainable development of resource-constrained communities" (p.1; also see Lucena et al. 2010; Mitcham and Munoz 2010). Our aim in writing this article is to engage young minds involved in the development and humanitarian engineering to reflect simultaneously and critically on the technical as well as the socio-cultural, sustainable, and equitable solutions for the benefit of disadvantaged and resource-constrained communities.

It came to us as no surprise that almost all of the engineering students in the summer course mentioned above primarily defined themselves as problem solvers. The literature supports this worldview (National Academy of Engineering, 2004; Downey 2005; Costner 2018; Koen 2003; Martijn 2015). Scholars such as Lucena et al. (2010) highlight how engineering as a profession has historically focused on problem-solving/industry-based approach. (Downey and Lucena 2006; p. 1), argue that "the technical five-step engineering method (Given, Find, Diagram, Equations, Solution) that is still taught regularly in engineering science courses is at the core of engineering curricula..." subscribes to either-or binaries. In other words, the five-step engineering method divides people into two groups-those who seek solutions and those who do not. Not only does this method eliminate the possibility of a spectrum of diverse viewpoints, but also, as we demonstrate later, epistemologically, such engineering method subscribes to the assumptions underlying modernization theory, which serves as a foundation for many international and humanitarian development projects.

By exclusively focusing on the problem-solving approach, the engineering curricula emphasize technical aspects, thus conditioning the engineering students to focus on the technical solutions (Gainsburg et al. 2010; Bucciarelli 2003). However, there is a growing realization that technical solutions alone are not enough for the long-term sustainability of development projects. In fact, a predominant focus on the technical issues can hinder one's ability to conceive a more holistic picture that requires paying keen attention to the sociocultural, historical, economic, and environmental impact of the project. In other words, in addition to technical literacy, humanitarian engineers need to develop critical socio-technical knowledge.

This is also recommended in the ABET's Criteria for Accrediting Engineering Programs (https://www.abet.org/ wp-content/uploads/2018/02/E001-18-19-EAC-Criteria-11-2 9-17.pdf) that engineering students should be able to design systems and processes within the economic, environmental, social, political, ethical, health and safety, manufacturability, and sustainability constraints. However, as Gainsburg et al. (2010) argue, ABET's criteria and recommendations are still not reflected in a majority of engineering curricula. It is often argued that it is not possible for engineering programs to teach about all (or even most) cultures in the world in order to equip students with the knowledge about economic, environmental, social, political, ethical, health and safety, manufacturability, and sustainability dynamics of each society they might be working in. Such critiques miss the point that it is not the knowledge of individual cultures but the principles such as epistemic humility, acknowledgment of the existence and veracity of local knowledge, etc., that opens ways to looking for locally relevant solutions. This can be done even with a handful of courses that engineering students may be asked to take in other disciplines.

The exclusive focus on technical needs has led to a model where the primary objective of development has been reduced to including the poorest in the global production processes for the benefit of industry, without any emphasis on uplifting the social conditions of those at the margins. The question that faces development workers-whether they are engineers or humanitarian assistance workers-is how we can make an epistemological shift where development is conceived in more holistic terms. In other words, how can the exclusive focus on the techno-economic conditions, resulting from ontological assumptions that view communities in terms of their deficits and not their capabilities and diverse knowledge systems, be changed? The answer to this question perhaps lies in reemphasizing the need to take into consideration the socio-cultural and environmental dimensions along with the techno-economic aspects of development projects.

According to Lucena et al. (2010):

...[while] the relationship between engineering and development began to take shape in the 19th century, engineering work with local communities has been problematic at best. Throughout most of this history, engineers have been guided primarily by commitments to top-down planning, design, development, and implementation of projects done without consultation with communities. (p. 42)

The relationship between humanitarian engineering and development is a recent one. However, it is predominantly reflective of the earlier relationship between engineering and development where, as noted by Lucena et al. (2010), the focus and emphasis is still 
predominantly on the technical aspects of design rather than the socio-cultural realities of the host society.

Had the engineers of the Green Revolution acknowledged that small-scale farmers held centuries-old knowledge about their local environments and ecosystems and consulted local farmers in planning the Green Revolution, the negative impact of fertilizers and monocultures could have been avoided. However, erstwhile mistakes can prove to be excellent learning opportunities.

\section{Unproductive success and productive failures}

While scholars have argued for a need to change the engineering curriculum (Downey and Lucena 2006), it is understandable such processes are not only political in nature but also require a longer time to enact. In this paper, we make a case for learning from failure as an effective route to developing socio-technical-critical knowledge. We challenge the belief that failure is necessarily a bad outcome. Furthermore, we also argue that tackled appropriately, failure can, in fact, be a path to success.

Kapur (2016) highlights the importance of productive failures for long-term learning. In the case of development projects, such emphasis on the long-term can mean the sustainability of the project. Drawing on the Schmidt and Bjork's (1992) idea of "desirable difficulties, "Kapur argues that design efforts, which focus on shortterm performance, should be labeled as "unproductive success" whereas designing conditions which may not maximize performance in short-term but lead to longterm solutions to the problem should be labeled as "productive failure" (Kapur 2016, p. 289; Kapur 2008; Kapur 2010; 2014). Kapur's largument seems quite appropriate when we analyze various development projects which focused on short-term performance, based on technoeconomic solutions alone. Although many were initially viewed as "success," they were unproductive in longterm sustainability and thus withered away without positively impacting the communities they were supposed to benefit. We posit that engineers and humanitarian assistance workers can turn development failures into productive failures through the application of critical socio-technical knowledge.

We are critical of the current way of looking at failure through the audit and report method. Various humanitarian engineering/assistance organizations use audit and report method to assess the outcomes of projects especially the ones that are not successful. We argue that using such practice is not conducive to converting the failure into a "productive failure." The audit of a failed project usually ends in a report which is internally circulated within the organization. The assumption behind such audit and report method is that the same mistakes may not be repeated in future projects. However, the audit and report method ignores the fact that the next project might not be in the same locale with the same population. In other words, audit and report once again emphasize looking at the project failure from a technoeconomic perspective. In a majority of instances, the final report is used to satisfy the funding agencies that an audit of a failed project has been conducted and the mistakes have been duly noted.

In 2008, Engineers Without Borders Canada started publishing its annual "failure report." According to George Roter, the CEO of Engineers without Borders, the EWB failure report is "fundamentally [a] way of instituting a practice, which reflects the spirit of innovation... across international development" (admittingfailure.com). In 2011, based on the Engineers Without Borders failure report, a website entitled admittingfailure.com was launched. According to the mission of the website, "we need a paradigm shift in how civil society views failure... This starts with open and honest dialogue about what is working and what isn't..." (admittingfailures.com). Engineers Without Borders see the failure report as a means of "working towards change in the development sector towards humility, innovation, and learning" (admittingfailure.com). Of the three objectives mentioned above, it is humility that is not only important but perhaps cardinal to understanding why even some of the most well-meaning, well-planned, and well-articulated projects (especially in the Global South) fail to achieve their objectives.

Let us briefly unfold the notion of humility as a cardinal principle of innovation and learning necessary for developing techno-social critical literacy. The development paradigm, just as the dominant Western knowledge system of which it is a part, has an epistemic arrogance, which bars it from recognizing other knowledge systems. Such epistemic arrogance is a result of what de Sousa Santos (2007) terms as abyssal thinking in which there is only knowledge on one side of the abyss, and on the other side, there is nothing, i.e., no valid knowledge. Abyssal thinking and epistemic arrogance (in development) are underlying elements responsible for the failure of many well-meaning, well-crafted projects. Thus, in our view, humility should not only be limited to admitting failures but more importantly, to acknowledge that ours is not the only knowledge system that has the power to identify, explain, and solve the development issues. Humility, in this sense, is to acknowledge the necessity of a "dialogical and dialectical relationship between the dominant and the... excluded and/or marginalized knowledge systems... on a level playing field, with the moral sincerity ... and a genuine desire to understand, include, and respect the genealogical, moral, historical, and intellectual roots and contributions of each knowledge system in the spirit of 
discovery and respect (Naseem and Arshad-Ayaz 2016: 14-15)". It is in the spirit that we discuss how failure can be turned into "productive failure," leading to a learning moment in the context of engineering and humanitarian assistance work in the field of development. However, this requires an epistemological shift that not only makes visible the fallacies of the abyssal thinking in development, but which also points to the availability of an alternate ecosystem of knowledge from which to seek solutions.

\section{Contemporary development discourses: major assumptions, tenets, and fallacies}

Development is a contested concept. In its post-WWII, especially the Cold War political manifestations, development was understood and articulated as a linear process in which societies go from point A (underdeveloped) to point B (developed). Discounting the agency and indigenous knowledge of societies (and their members), this polar-dichotomous articulation sees a significant role for the external actors in "helping" nations to move from point $\mathrm{A}$ to $\mathrm{B}$-from underdevelopment to development. During the Cold War period, development theory and its politico-economic manifestations such as the Point Four program and the Marshall Plan had a twofold objective: first, to rebuild/reconstruct a warravaged Western Europe as a bulwark against the Soviet Union and, second, to woo the newly independent states (the ex-colonies) to the capitalist bloc. Development thinking during this period assumed that the "reconstruction" (in Europe) and "development" (in the newly decolonized countries-hereafter Global South) would follow the same linear progression. Such thinking erroneously assumed that all societies are the same and thus going through the stages of development will ensure that they get to the desired outcome-industrialization and rise in GDP-and hence development. However, the fallacies of development theory soon became evident, as did its political agenda. Despite the obvious shortfalls of the theory and its associated models, development theory in its various manifestations (for example, structural adjustment, etc.) is still prevalent and dominates the discourse that guides development activities especially in the Global South. Below, we survey some of the major tenants and fallacies of contemporary development theory/studies.

\section{Main tenets of development theory (DT)}

Grounded in the modernization paradigm, development theory centers on one major theme-economics. Most of the approaches, as well as the discourses regarding development, revolve around economics-based policies and foreign aid. Modernization theory provides an economic lens exclusively to explain the underdevelopment of some states and to offer various forms of assistance to help "improve" the monetary situation in those developing states. However, as critics of development theory point out, the relationship between developed and underdeveloped countries mirrors a dialectic that is riddled with neo-colonial tendencies and inequality and that foreign financial aid, which usually comes with many strings attached, can have disempowering social, political, and financial repercussions.

As Kothari and Minogue (2002) argue, "development is ridden with paradoxes" (p. 1). These paradoxes have been highlighted by scholars working in the field of Critical Development Studies (CDS), which seeks to bring out the fallacies of the mainstream DT that include ahistoricism, dualism, uneven power dynamics, monocausalism, and the hegemony of Western epistemology, to name a few. Bonsu (2019) describes the cyclical nature of development by arguing that "whichever way one looks at it, the circle loops back for the benefit of the sponsors of development and the well-being of their own constituents" (p. 266). In the following sub-section, we elaborate on some of these fallacies in more detail.

\section{Ahistorical framing of development/under-development}

One of the central tenets/fallacies of the mainstream DT is the ahistoricization of development/underdevelopment in the Global South (GS). DT assumes that the starting point of development for the countries in the GS is the point at which they gained independence from the erstwhile colonial powers. It further assumes that should the countries of the GS follow the Rostowian stages of development, they should achieve the logical desirable goal of "development." These assumptions, however, ignore the historical dynamics of colonial plunder that had not only economic but also serious social, psychological, and political consequences for the future development of these societies. As Tharoor (2016) so forcefully demonstrates through the case of British colonization of India, the British actually underdeveloped India. At the time of the British incursion, India's "share of the world economy was 23 percent, as large as all of Europe put together... By the time the British departed India, it had dropped to just over 3 percent" (pp. 38-39). Additionally, there was systematic deindustrialization and demolition of India's artisanal industries (Tharoor 2016). It took India many decades to recover from the historical dynamics of colonialism.

Additionally, ahistorical narratives are used by explicitly focusing on fabricated timelines and dates to manipulate the data as well as the opinions towards policies that would seem sound according to the limited information provided within the vacuum of the timelines mentioned above. This concern is best voiced in the following statement by Andrews and Bawa (2014), "It is 
problematic to set straightjacket timelines for the discussion of a field that is both diverse and overlapping in theoretical, methodological and conceptual orientations" (p. 923).

To provide suggestions for successful development policies, experts have to look at history as a whole, in order to make sense of the different changes, cycles, approaches, and debates that have been occurring over time so that they have a better understanding of the present situation they are critiquing or looking at, a thing that can only be achieved by studying the underlying issues that have historically motivated various actors to "help" less developed countries (Bonsu 2019).

To fully understand the dynamics of development or the lack of it in the societies of the Global South, it is imperative to keep in view the historical dynamics of "underdevelopment" emanating from the process of colonization including but not limited to the financial plunder, deindustrialization, the colonial cultural projects, etc. It is imperative to understand the necessity of historical analysis in order to understand the errors of the past and to avoid the potential fallacy of reinstating colonial ways of knowing and doing.

\section{Dominant discursive constructions of development}

As mentioned above, DT seems to have a systematic dispensation for limited or misleading articulation, through arbitrary timelines and selective analyses. Ahistoricism is used as a tool to promote dominant narratives and themes that influence public opinion, research, and policy alike. The problem with the way development has been portrayed in the dominant discourses so far is that it is only understood in the Rostowian and/or neoclassical economic meaning. Such discursive articulation of development also sets into motion processes such as othering, superiority, and benevolence in the relationship between the donors and the recipients.

Development in today's world is almost exclusively seen in terms of poverty relief through foreign monetary aid and benevolent solidarity amongst nations-donors and recipients (Adelman 1999; Bonsu 2019; Okech \& Musindarwezo, 2019; Robinson-Pant 2001). The problem with this notion is that little attention goes into how vague and limited these donor-recipient associations are beneath the surface. Although the scholars mentioned above use different lenses to dig deeper into what development is and what it stands for, they all conclude that development, in fact, goes beyond the simplistic mainstream association with charity and monetary aid. Shiva (1993) highlighted the blindness of the development discourse to local knowledge and complete disregard of the ongoing capacities of the society. She deconstructs the myth of advanced consumption as the best possible development and calls for living "by transcending polarities - between people and the planet, between modern science and indigenous knowledge, between environment and development, between North and South, the local and the global" (Shiva 2009, p.79).

Adherence to seemingly simplistic and objective costbenefit analysis of the complex relationships between aid and development can lead to dangerous ideas. Before his article was rescinded from the Third World Quarterly, Gilley (2017), for example, suggested that the "objective costs/benefits approach identifies a certain need of human flourishing -development, security, governance, rights, etc. - and [asked] whether colonialism improved or worsened the objective provision of that need" (p. 2). According to Gilley, development means human flourishing in an economic cost/benefit context and thus makes a case for voluntary recolonization of previously colonized territories and states in order to achieve successful development. As we argued above, not only that the colonization was not a benign objective process, it also resulted in the crass plunder of the colonies. The recolonization argument based on a purely cold economic logic is replete with ahistoricism and the cherry-picked examples that are taken as evidence for paradoxical statements for "significant social, economic and political gains under colonialism: expanded education, improved public health, the abolition of slavery, widened employment opportunities, improved administration, the creation of basic infrastructure, female rights, the enfranchisement of untouchable or historically excluded communities, fair taxation, access to capital" (p. 4).

Recently, in the wake of the worsening environmental crisis, there have been calls for a more holistic approach to development in which the Global South and Global North work toward a common future (Horner and Hulme 2019). While, in principle, the approach seeks to find a holistic approach to deal with development issues both in the Global South as in the North, it also undermines the rightful Southern critiques and opinions by diluting their issues with those of the North. Similarly to Gilley's logic, this alternative does not take into account that the Global North and South are different and that even though they might share similar problems, the causes of those issues are not the same. Therefore, onesize-fits-all solutions can be disastrous. The reason for poverty, hunger, and general lack of prosperity in the Global South is based on the systematic and historical "civilizing missions" (Bonsu 2019, p. 261), and the narrow techno-economic development projects, Structural Adjustment Programmes (SAPs), that have led to the depletion of recourses, a loss of local epistemologies, sociopolitical implications whose aftermath we are still witnessing today in terms of discrimination, illiteracy, 
health concerns, etc. As opposed to this, the Global North's issues of homelessness, poverty, and hunger, which are equally unfortunate as the ones as the South, have different causes such as bureaucracy and inhumane fiscal policies amongst others. It is, thus important to understand that mono-causalistic explanations for complex development phenomena not only distort reality but also can (and do) lead to ineffective and decontextualized development planning.

\section{Monocausalism}

Regarded as one of the major fallacies in (DT), monocausalism refers to a focus on a single issue as the main reason for the underdevelopment of a society. Both success and failure of development projects are often attributed to single-factor explanations-often economic. Adelman (1999) criticizes this economics-oriented single cause attribution of underdevelopment, particularly the policies it inspired from a simplistic "one size fits all" outlook.

Furthermore, she reiterates the importance of an interdisciplinary and multifaceted approach. According to her:

... development policy requires a more complex understanding of social systems which combines economic, social, cultural and political institutions and their changing interactions over time; that interventions may have to be multipronged; that what is good for one phase of the development process may be bad for the next phase. (p. 2)

Adelman's views and concerns are shared by many scholars who examine macro-level development. This shift is further evident in the Post-Development line of thinking, which questions the focus on the implementation of Western concepts of economics on problems in the Global South. According to scholars such as Gudynas (2011), “... perhaps the more serious problem is that well-known critical stances focus on capitalism, not development" (p. 88).

While some scholars call for abandoning the traditional notion of development altogether, critical scholars such as Munck (2019) suggest that "the challenge of critical development theory cannot be met by moving beyond or giving up on development. Rather, the challenge is to imagine and practice development differently" (p. 45). The way to proceed for more equitable development, according to Munck, is to look at development from different perspectives and frameworks such as the feminist, ecological, or global lenses, to name a few. Another way would be the implementation of an interdisciplinary approach in terms of critical contextualized policymaking in order to combat the simplistic, monocausal understanding of problems in some Third World countries' economic development. As Adelman (1999) writes:

... we seem to be unable to admit that the X-factor does not exist; that development policy requires a more complex understanding of social systems which combines economic, social, cultural and political institutions and their changing interactions over time; that interventions may have to be multipronged; that what is good for one phase of the development process may be bad for the next phase. (p. 2)

Adelman's statement is extremely pertinent to the issues mentioned above. The close association between development and compartmentalization is a dangerous one, for it only leads to limited outlooks and results.

\section{One-size-fits-all solutions}

A related fallacy of the mainstream development theory is the misguided notion that what works in one situation (usually in the West) will work equally well in all development contexts. In other words, the one-size-fits-all approach often advocated (and implemented) by the donors and multilateral institutions has seen its limitations exposed in a large number of development projects in the Global South (Naseem and Arshad-Ayaz 2016). An example of this can be noticed in the way most development projects are catered towards optimal economic benefit à la Western neo-liberal values and might have little or no positive consequences for the local needs of the developing societies. Bonsu (2019) talks about the failure of DT and its advocates, to moderate between both the Western and local views on development due to the dominant practice of paternalism which leads to the neglect of the local knowledge and the imposition of a strictly Western-oriented approach when dealing with a country's resources.

\section{Paternalism and infantilization-the big brother knows all approach}

There is an uneven power dynamic between both the "developed" and the "developing" societies. This power dynamic is evident in the way in which the dominant discourse on development is presented and enforced. For example, the infantilization of underdeveloped countries by the developed countries is particularly visible in the genealogy of mainstream development thinking's rhetoric of "developed/civilized savior" presented on multiple occasions and policies throughout time (Veltmeyer 2011). For example, Arshad-Ayaz et al. (2017) while analyzing 2015 White Paper on Global Citizenship written by the Canadian youth argue: 
Even though the White Paper critiques voluntourism and its negative implications, it does not dismantle the discourse of 'helping' within which it operates. While the desire to help is often linked to good intentions, in order to construct others as being in need of help, and global citizens as dispensers of such help, an 'us' and 'them' binary is required. This binary sustains a hierarchy that places Western knowledge as knowledge of universal worth and local knowledge as having only contextual worth. (Arshad-Ayaz et al. 2017, p. 25; Andreotti 2011)

The savior mentality is translated into the infantilization of the "underdeveloped" locals. RobinsonPant (2001) cites a song written by a young Nepalese woman, Chameli Ghimre, for "Education Day" to highlight how the lyrics to the song show the Western paternalism. Consider the verse, "We spent our lives pounding and grinding grain, collecting firewood and fodder... It is father's and mother's fault for not sending us to the village school" (p.317). The verse displays a dangerous undermining of local traditions, epistemologies, and values-by pointing the blame at parents and ignoring what could be the causes (historical, contextual) for the way things are.

Furthermore, this idea that the western literacy is the only valuable form of education creates a power dynamic that will only serve the purposes of the western developers by making the locals disregard their own ways of knowing and doing. What is wrong with pounding and grinding grain? Is not that also a type of education and (work) that keeps people sustained and alive? The historical context for the reason for the underdevelopment of those countries is rarely mentioned; in most cases, the infantilized countries and societies are depicted as victims of poverty and natural disasters instead of victims of continuous conquests, exploitations, and failed socioeconomic experiments, who happen to be dealing with poverty and other disastrous situations as a direct consequence of the former.

\section{Neglect of local cultures/knowledge}

As stated by Bonsu (2019), colonialism and the mainstream development ideologies share a close connection. The following statement from Lord Durham's (1839) report on the French Canadians in British North America at the time illustrates Bonsu's point further:

there can hardly be conceived a nationality more destitute of all that can invigorate and elevate a people, than that which is exhibited by the descendants of the French in Lower Canada, owing to their retaining their peculiar language and manners. They are a people with no history, and no literature. (p. 95)
Durham's comments are not only clearly ahistorical and portray the French Canadians in the vacuum of British colonialism, but they also aid him in justify assimilatory practices that would ultimately be presented in linguistic and cultural restrictions on the French Canadians in an attempt to develop the French Canadians by making them English. This notion is also present in the way in which local knowledge and epistemologies are disregarded due to the paternalism practiced by the various development actors: researchers, businesses, organizations, policymakers, volunteers, etc.

Examples of epistemic racism, such as evident in Lord Durham's thesis on French Canadians or Lord Macaulay's Minute on Indian Education, are also visible in the modern-day development discourses. Chameli's song (as cited by Robinson-Pant (2001)) is but one such example. The songwriter not only mentions how positive change and progress are brought through the western "eye-opening" education but also the self is named and understood "through this important education" (p. 317) which teaches the children to "write" their names. No doubt learning how to read and write can be beneficial. However, it is important to note that here the song is glorifying the Western literacy skills, as opposed to the field and housework, also pivotal skills that allowed them to survive and maintain their livelihoods. This overemphasis on Western (colonial) norms of literacy, as opposed to local principles in underdeveloped countries, is the norm in most cases (Bonsu 2019). This marginalization of local ways of knowledge stems from the insufficient historical context, simplistic understanding of the situation in these communities and countries, and the standardized solutions promoted in almost all environments regardless of the linguistic, social, cultural, or even ecological contexts. Let us conclude this subsection with the example of Lurimaya (cited in Robinson-Pant 2001), a low caste woman who got expelled from a women's group for not attending "enough" literacy classes. Even though the woman was more than capable of surviving in her milieu without reading or writing, she did not conform to the cookie-cutter approach to Western development, as mandated by a Western NGO, and thus was seen unworthy of further development (p. 320). One cannot help but wonder why is literacy or illiteracy only seen as related to skills like reading and writing, especially when it is established that there are multiple literacies and different people learn differently in different contexts? In the following space, we take some "failed" development projects, which, while well-intentioned and technically sound, suffered from the fallacies of the mainstream development discourse and thus failed. These, in our opinion, are instances of failures from which we can learn. 


\section{Learning from failure}

Global South has a long history of being colonized. As discussed above, most of the development projects and campaigns do not take this into account while conceiving, designing, and implementing developmental or humanitarian projects. Such epistemic amnesia limits the scope of the issues and masks the legacies of colonization. Furthermore, these societies have a distinct cultural, political, and social ethos that makes every community a unique case. Neither the problems (humanitarian or developmental) nor the solutions in/for each of these societies are the same. Each, thus, requires to be understood in its particular historical, cultural, social, and economic context. Below, we discuss four cases of development and humanitarian assistance that were largely oblivious of the historical, cultural, social, and economic dynamics in four African societies, thus failing. We argue such past failures can be used as teachable moments and converted into "productive failures" (Kapur 2016) from which development planners can learn about making development projects sustainable and relevant to the local needs.

\section{The Bovine Mystique: Thaba-Tseka Development Project (Lesotho, 1975-1984)}

Lesotho is a relatively small landlocked country nestled in the middle of South Africa. A country, previously known as of Basutoland was a British protectorate until its independence in 1966. Lesotho has been the subject of various rural development projects, most of which have not had a large-scale impact due to discrepancies between how the development thinking understood Lesotho and how Lesotho is in reality. One of the bestdocumented projects has been the 1975 Thaba-Tseka Development Project, a joint project between the UN's Food and Agriculture Organization (FAO), the World Bank (IBRD), the Canadian International Development Agency (CIDA), and the Government of Lesotho (GOL).

The project conceived its goals on the assumption that Lesotho is a country of farmers who live in isolation and lack of exposure to modernity, which hindered its agricultural and economic development. Moreover, it was presumed that isolation had kept the farmers of Lesotho trapped with large quantities of low-quality nonproductive cattle. Thus, the objectives of the ThabaTseka development project targeted three things: mitigating isolation through infrastructure and road links between the mountainous area and the capital city of Maseru (Ferguson 1994, p. 75); increasing livestock and agricultural production, through the introduction of superior cattle breeds; and improving grazing pasture through privatization. Despite technically achieving the three targets, the project failed to have any significant impact on local people.
While the objectives of the Thaba-Tseka project were well-meaning in principle, they were inadequate and inappropriate for Lesotho due to the misunderstanding about the reality of the country. One of the most prominent instances of this is the attempts to improve the situation of cattle, particularly during droughts. The project managers' approach was narrow and strictly based on the Global North's idea of economic-based development. This was evident in the constant attempts to get the owners to sell and understock the cattle. These attempts were culturally blind to how the people of Lesotho functioned and resulted in years of dragged-on tensions among the locals and also between the locals and the development workers. For the male villagers, the cattle were the only agreed-upon form of increasing and maintaining social capital. Since most of the men work in the South African mine industry, the cattle served as a place holder for the contribution of the "man" in the well-being of his community, as well as a symbol of his dominant status in the household. As opposed to cash, cattle are seen exclusively as a man's property.

Furthermore, the cattle also serve as a retirement fund, only to be sold as a "declaration of destitution" (Ferguson 1994, p. 159). The size of the cattle is seen as a more prestigious source of wealth, regardless of its productivity. Oblivious of the sociocultural realities of the locals, the project managers saw the cattle as unproductive. Focusing on the economic aspect, project managers viewed cattle in two ways: (a) an economic burden because of their overconsumption of the pasture without actually generating any income in return and (b) an asset capable of being converted into financial gains by selling them off. Development workers and locals had very different priorities. For the villagers, the size of the cattle-herd and its endurance was more important socially. The project managers focused on the economic and the technical side, the optimal solution for the development workers was villagers should sell their cattle and invest in a smaller amount of superior breeds that will produce economically profitable returns.

When villagers decided not to subscribe to the development solutions offered by "experts," the project managers blamed the locals, particularly the men's lack of insight. Ferguson (1994) notes how the infantilization of the villagers, by the project managers, was evident in the way in which they regarded the peasants as people who "lacked education, that they did not understand the proposals, that matters needed to be explained better" (p. 186). Ferguson suggests that the ignorance is not on the part of the villagers but the managers'; he states:

the Thaba-Tseka officials who lectured so long and hard at the village meetings were, without particularly intending to, entering into a long-established 
ideological dispute over privileges and protections granted livestock as a category of property. And, again without particularly intending to, these officials, all men, entered this dispute on the side of the women. (p. 187)

The inappropriate development schemes, negligence of the local culture, and reality, along with the managers' assumptions of the superiority of their knowledge system, contributed to making this project a source of tension for everyone involved in it. The problems could have been mitigated through a proper understanding of the cultural, social, economic, and historical dynamics of the Lesotho society before coming up with solutions for their development problems. Failure of the Thaba Tseka project is an ideal example of learning from the shortcomings of significant assumptions, tenets, and fallacies of the mainstream development discourse.

\section{The Norwegian Agency for Development Cooperation (NORAD) Fish Processing Plant (FPP) (Kalokol, Kenya, 1978-1981)}

Over the years, Kenya has been subject to severe droughts and famines, which forced many of the pastoralist nomadic and semi-nomadic tribes to seek refuge in famine relief camps or just wait out the harsh conditions close to Lake Turkana. The fact that the droughts were reoccurring meant that this increase in the population density was going to be a frequent problem for the resources in the area and its people.

In an attempt to mitigate the severity of these consequences, the Kenyan government reached out to Norway in the 1960s to help with the dire situation in Lake Turkana (erstwhile Lake Rudolph) region in Northwestern Kenya. The consultations between the two countries resulted in the conception of the Kenya/Norad Lake Turkana Fisheries Project. Initially, the project aimed to provide equipment to facilitate fishing in Lake Turkana. Nonetheless, after establishing the Turkana Fishermans Co-operative Society (TFCS), the project shifted its aims and began focusing solely on supporting the expansion and development of the (TFCS) in 1968. This change in focus led to the fish processing plant project in 1978 (Jorgensen et al. 1980).

Given the local situation, the FFP was a hugely ambitious project. From the Norwegian standpoint, this project was seen as the next logical step in an economic development scheme for the region. Nonetheless, for the pastoralists, fishing was not their calling; it was merely a tool for survival. As a matter of fact, most of the extra income earned from fishing was used to purchase cattle to revert to their original lifestyle. The massive factory would be run by the TFCS, and Norad had allocated space for various fish processing methods from cleaning, gutting, filleting, salting, and freezing, as well as the suitable technologies and equipment that would facilitate the transit from fish to market/consumer. Nonetheless, 1 year before the project was to be completed, discrepancies in Lake Turkana, as well as some issues related to shortcomings from the TFCS, led to Norad's employment of an advisory group to evaluate the feasibility of the FPP.

The advisory group evaluation stated that the very nature of the FPP would have a devastating impact on the local economy. Due to the employment of various technologies, recourses, and means of transport, the cost of the fish will have to increase to generate profit and revitalize the economy. However, the evaluators did state that almost every other traditional method of fish processing, such as salting or drying, could have a better profit margin given the lower transportation and preservation costs. Additionally, the quality of fish as well as the relatively small scale of operation the processed fish products will not be able to compete on an international level, which meant that that the local market was limited, as customers were not extremely keen to consume fish (Jorgensen et al. 1980, p. 44). Based on the report, it seemed that the expectations for economic prosperity were misplaced and the mechanization will inevitably cost people, mostly women, their livelihoods rather than generating extra income. As a result of this evaluation and various other developments such as the Lake's ecosystem, the FPP although completed was never put to work. According to another evaluation report published in 1985, the FPP will most likely never be utilized in the future. The evaluation led to the recommendation, which states that the "TFCS operation must be kept as simple and flexible as possible, avoiding at all costs over sophistication with the high cost and high technology components" (Watson et al. 1985, p. 64). The project overestimated the target market and the local situation as well as the implementation of projects and technologies that were not suitable to the area, the people, or their needs.

The project carried out by Norad displayed a myriad of common mistakes by development aid projects such as excessively narrow techno-economic focus and one size fits all solution. The FFP, as well as the Lake Turkana Fisheries Project, was conceived following generalized, do good proverb that overarches a majority of the development projects around the world-"giving a man a fish to eat provides him with food for only one day, whereas teaching him to catch fish creates the possibility of his feeding himself and his family throughout their lives" (Watson et al. 1985, p. 7). In the case of Lake Turkana, giving a man a fish and teaching him how to fish were not beneficial in the long term, for he was not a fisher but a nomad and had no intention of changing 
his lifestyle. As evident in the Norad report, "the Turkana ethnic group, was cattle farming, and fishing did not appeal to them as a way of life" (Norwegian Agency for Development Cooperation 2014). The introduction of fishing as a supplement to facilitate survival via basic equipment and information could have been more beneficial and cost-effective. Norad admitted that the fisheries project failed because of the gross ignorance of the local situation and culture. Furthermore, the introduction of the fisheries project in the area also disturbed the traditional balance of local power. Those benefitting from the project started discriminatory practices towards others in the locality, thus throwing awry the power dynamics in the area which resulted in social and political conflict.

\section{Cookit solar cookers project in Kakuma Refugee Camp (Kenya, 1995)}

In general, many African countries suffer from drought, desertification, and many other environmental issues that do impact the well-being of its inhabitants. In many cases, the struggle for recourses has caused several humanitarian crises, such as illnesses, famines, and wars that have forcibly displaced people out of their norms, traditions, and lands. A direct impact of these calamities is on the traditional food habits, in terms of quality/ quantity of nutrition, the cooking methods, and fuels used for optimal sustenance. Traditional energy and fuel resources such as firewood or charcoal have become scarce and are becoming a source of tension between refugees and the citizens of their host countries. Many relief projects looked at the introduction and integration of renewable energy into people's dietary habits ("as a beacon of hope") that would improve the people's overall health as well as preserve the environment.

In 1995, Solar Cooker International (SCI) introduced the first large-scale solar cooking project to the Kakuma refugee camp located in the district of Turkana, Kenya. The project aimed to help local communities in their use of solar energy to "cook food and pasteurize water for the benefit of people and environments" (Center for Independent Research and Energy for Sustainable Environment, 2003, p. 4). The solar energy cookstove "Cookit" was seen as one of the most basic and easy alternatives to the other options available. Upon purchase, each kit would contain the solar panel (Cookit), plastic bags, a detached water pasteurization indicator (WAPI), and an instruction manual. Although noble in its intentions, this project had various flaws and shortcomings in terms of its target population, which could explain the minimal impact and local interest or use over the years (Kaburu et al. 2019).

As envisaged in the mission statement, the project had a dual purpose-to cook food and pasteurize water while preserving the environment. Nonetheless, with its notorious heating/cooking time (Baptista et al. 2003; McArdle 2016), the dual use of the cooker was not a viable option, thus requiring at least two different cookers: one for pasteurizing water and one for cooking. The design of the cooker did not consider the number of members per family. Most of the stoves were designed to provide a meal for 5-6 people. However, most of the families in the project area have more than six members due to polygamy and other household ties and relationships; this critical local cultural and social fact was ignored in the project design.

Furthermore, the lack of proper understanding of the particular circumstances of the refugees and how their traumatic experiences play a role in their day to day tasks are evident in almost all the literature promoting solar cooking kits. The cooker was marketed with the stated attraction that one can leave the food to cook itself while going about other things (Hanna and McArdle 2016). With the refugee population, issues of food security arise due to the rations and insufficient quantities of food distributed. This made people reluctant to leave the food unattended as it might be stolen (Kaburu et al. 2019). Another issue regarding safety is the detached indicator (WAPI). The fact that this indicator is detached makes it susceptible to loss or damage. In some cases, people forgot if they had used it or not, thus leading to many instances where people resorted to "guesswork" which raised the risk of drinking unpasteurized water that could be a potential health threat to people (MacClancy 2014). The project was considered a failed problem-solving attempt. While it did deliver on its promise in terms of providing a tool to pasteurize water and cook food, however, the project failed as developers were unable to factor in the vulnerability of people in terms of particular living conditions, scarcity of resources, and unfamiliarity with the technology in a refugee camp.

Ultimately, what led to the failure of a sustainable uptake for the solar cooker project was the fact that it did not adapt to the needs of the people as much as it required adaptation from them. In many respects, the use of Cookit demanded from the users a change of culture, for instance, the fact that the Cookit was ideal for a (Western-style ) small family and not large families, the fact that the Cookit yielded best results when fixed recipes and time was used for meal preparation (perhaps ideal for working women but not for women who are not allowed to read the refugee camps), the fact that recipes called for a consistent supply of ingredients from the market (Western-style), and the fact that the detached water pasteurization indicator (WAPI) needed constant maintenance of delicate solar panel which was not possible in a densely populated refugee camp such 
as Kakuma. As if using Cookit did not ask people to make lifestyle changes enough, the developers decided to add purchase fees. While this might be a standard practice in humanitarian engineering contexts to have a for-profit business plan, in this particular humanitarian context the purchase fee proved to be a key factor in the failure of the project, which further decreased its widespread utility. Additional expenses related to the upkeep of the kit (painting the pots), purchasing plastic bags, and having to purchase more than one Cookit to be able to provide for a $6+$ member household, not to mention the predisposition of the solar panel to wear and tear from the unfavorable weather conditions in Kakuma, made this Cookit an expensive inconvenience for the local population, although developers knew that the refugees will be less likely to use the solar cookers if they had to buy them. The failure of the project was footnoted as "donor dependency syndrome." In the case of a refugee camp, with limited resources, where shortages are more often than not the norm, one cannot help but wonder if such labeling was not to blame the "underprivileged" for their prudence and self-preservation. Almost 16 years later, this is still the case for most refugees. As Kaburu et al. mention:

Refugees generally do not have work permits in their hosting countries thus cannot engage in gainful employment. This affects their purchasing power and choice. They must rely on aid supplies from humanitarian agencies for essential commodities and services like shelter, food, fuel, and clothing. (2019, p. 14)

It is clear that these refugees are already the underdog in those situations. They live in conditions where they constantly struggle for scarce resources. A majority of times they have to scavenge, barter, or succumb to the whims of relief and aid agencies, which limit their autonomy over the most basic of human essentials. It is important that the abovementioned dynamics are taken into consideration when designing and evaluating humanitarian aid projects.

\section{Clean cooking in Domeabra: the Twig-Light project (Ghana, 2008)}

Environmental and health issues arising from the use of traditional cooking stoves and fuels seem to be a general concern in Africa. Similar to the intentions and efforts in the solar cooker project in Kenya, in 2008, students with the GlobalResolve initiative at Arizona State University (ASU) introduced smokeless ethanol stoves (SES) to mitigate some of the health problems caused by the indoor air pollution occurring from traditional firewood cooking. Upon the introduction of the stove prototypes, this project was not met with enthusiasm by the villagers who did not perceive a need for improved cookstoves. To the locals, the firewood smoke did not seem a concern. The smoke kept mosquitoes and other bugs out of their huts. Although the GlobalResolve initiative provided a well-intended and decent cooking fuel alternative, the students in this project failed to recognize the local reality of the villagers in that regard. To further understand the reasons for the SES's lack of local success, a mapping process was employed. The results from the mapping efforts showed that in the case of the villagers in Domeabra the SES were bound to fail due to factors related to family size, cooking style and preferences, the actual prototype design, and ultimately the relative ease of access to a free source of fuel, firewood.

Each stove was designed for a family of five, but in the village 10 to 20 family members often lived together. In addition, the dietary staple was a very thick porridge that required vigorous stirring, but the original ethanol stoves were tall and skinny and could not stabilize the pots that were traditionally used. Finally, the villagers did not understand why anyone would put forth the time and effort to brew ethanol as a fuel when there was plenty of free firewood just a short walk away. (Wetmore 2012, p. 44)

Similar to the Kenyan Cookit project, the narrow focus on the techno-economic aspect led the developers to at best a "superficial" understanding of the local culture and needs. The efficiency, price, and capacity of these cookers and stoves were designed and studied to meet the needs of a family in the West. However, in the case of both Ghana and Kenya, the need and cost analysis were not accurate due to a lack of knowledge about socio-cultural factors of the particular context. The target populations' socio-cultural reality, larger family sizes, and purchase power made the SES financially, socially, and culturally unfeasible, making scavenging for wood more sensible. While the SES was incontestably the most efficient and affordable option in the market at the time, these stoves were not marketed to the right consumers. Local priorities of the target population were access to affordable lighting and power. This led to another prototype project, the Twig Light, a simple, affordable device that would provide a source of light to its users. The prototype the Twig Light was well received, and the villagers began asking for alterations and improvements to the final product in ways that would serve their needs better.

The contrast between the SES and the Twig Light projects is a good example of Engineering Problem Solving (EPS) in a development/aid context. While there is a general move in Africa towards green energy and 
alternative energy sources, this gravitation is mainly promoted by governments, international development agencies, and most recently international private corporations. The people themselves are more interested in their day to day survival and general comfort; the upkeep of the environment at the cost of a cultural change or putting in more economic resources does not seem to be a priority.

The smokeless ethanol stoves and Cookit projects did not supplement the cooking habits/culture of the villagers but rather inconvenienced them. On the other hand, the Twig Light project used the technology to facilitate and blend in the mundane social and cultural activities of the villagers. Twig Light utilized leftover embers to function-a commonsense decision to maximize the utility of the fuel recourses that the users had at their disposal, in this case, leftover coals from cooking (Rogers et al. 2010). Another reason for the acceptance of the Twig Light was its potential as a tool to recharge their cell phones and small devices, something which was valuable for the villagers. Additionally, Twig Light project developers heavily consulted with the locals via various interviews, surveys, and mapping appraisals; the locals felt a part of the project and provided critical information needed for the further development of the prototype. The direct inclusion and involvement of the beneficiaries and their input and feedback in the evolution of the device made them more willing to pay the extra cost for the improvements to the prototype, such as the cell phone charging circuit, even though they had expressed the importance of a low-cost product.

\section{Conclusions}

Common to all of the examples mentioned above are a set of common fallacies inherent in the mainstream development discourse. Most of the inconsistencies can be mitigated with humility on part of development planners, i.e., admitting that there is local knowledge that can contribute to relevant and contextualized project planning. Additionally, engineers and humanitarian aid workers will benefit from an in-depth understanding of the local social, cultural, political, and economic ethos for a holistic understanding of the situation rather than a narrow focus on mere techno-economic solutions. Ferguson (1994), in the case of Lesotho, points out the importance of scrutinizing any kind of information, no matter the source. Dwelling deep into the worldviews of the locals would have been particularly beneficial in the case of Thaba-Tseka where most of the money could have been utilized in a manner advantageous to the people without stepping on their cultural values.

Similarly, in Lake Turkana, the attempt to promote fishing as the only solution for the nomadic destitute Turkana people overlooked their culture, traditions, and values. The project resulted in unfortunate consequences in terms of creating further power imbalances between the locals. Such overlooking of local knowledge systems and cultural values is also evident in the attempts of implementing renewable energy. Solar and smokeless cookers/stoves were well-intended, however, extremely impractical in terms of local culture, finances, time, and space. On the other hand, the GlobalResolve Twig Light project in Ghana highlights the importance of consulting with the locals and coming up with innovative solutions and gadgets that facilitate the local populations' way of life instead of trying to alter it according to Western standards. In all of the projects discussed above, it was realized that these projects were not viable for the local lifestyle. Conceptually, the biggest lesson to emerge from conceiving these projects in the light of the notion of productive failure is that the Rostowian stages of development are not applicable to all societies uniformly. Invoking the notion of productive failure can help us see what we can learn from these mistakes and how we can pay more attention to not repeating these mistakes next time.

Engineers and humanitarian aid workers need a paradigm change for designing products, systems, or services to support the sustainable development of resource-constrained and marginalized communities. Using intellectual humility that acknowledges diverse knowledge systems and through proper and detailed historical accounts, future failures can be mitigated. There is a possibility of transitioning to a new paradigm where a more humble development discourse would rely on learning from the failures of the past to guide the present and shape the future. As Munck (2019) states, "the binary oppositions of formal/informal and of precarious versus stable work join a long list of debilitating constructs, such as employment/unemployment, that we need to supersede if we are to develop a transformative critical analysis" (p. 2). An example of such a supersession is visible in the Latin American notion of Buen Vivir. The notion of Buen Vivir is loosely translated to living well. According to Gudynas (2011), "any alternative to development must open paths to move beyond the modern Western culture" (p. 442). Buen Vivir does not separate nature from humans. Moreover, it does not dwell within the capitalist/socialist binaries. These two tenets make Buen Vivir a good candidate for a successful alternative view on the mainstream approach to development. Buen Vivir is but only one of the alternative approaches through which to see and understand alternative ways of development. As de Sousa Santos (2007) suggests, we need to turn our attention to post-abyssal thinking that recognizes an ecology of knowledge and alternative places to seek different options. 
As stated earlier, our objective in this paper is not to critique the emergent sub-discipline of humanitarian engineering. Nor it is to put engineers, especially the younger minds in the field on a spot. Ours is a humble effort to point out how a paradigm shift can result in better utilization of scarce development resources, thus benefitting the people already ravaged by natural and man-made calamities. The field of humanitarian engineering can benefit from further research in areas such as how to make the academy (natural and social sciences, medical and engineering programs) more transdisciplinary and how to create spaces where conversations between students from seemingly incommensurate epistemological positions can take place.

\section{Acknowledgements}

We thank the anonymous reviewers for their helpful comments.

\section{Authors' contributions}

All authors read and approved the final manuscript.

\section{Funding}

No outside funding was used to support this work.

\section{Availability of data and materials}

Not applicable.

\section{Competing interests}

The authors declare that they have no competing interests.

Received: 20 March 2020 Accepted: 19 May 2020

Published online: 27 June 2020

\section{References}

Adelman, I (1999) Fallacies in development theory and their implications for policy (No. 25005). Retrieved from University of California, Berkeley, Department of Agricultural and Resource Economics website: https://ideas.repec.org/p/ags/ ucbecw/25005.html/admittingfailures.com. Accessed February 14, 2020.

Andreotti V (2011) Actionable postcolonial theory in education. Palgrave MacMillan, New York

Andrews N, Bawa S (2014) A post-development hoax? (Re)-examining the past, present and future of development studies. Third World Q 35(6):922-938 https://doi.org/10.1080/01436597.2014.907704

Arshad-Ayaz A, Andreotti V, Sutherland A (2017) A critical reading of The National Youth White Paper on Global Citizenship. International Journal of Development Education and Global Learning 8(2):19-36

Baptista, T. , Curnow, K., Hiranaga, B. , Magnus, B. , \& Perry, D (2003) Solar household energy, incorporated: a market-based strategy for introducing passive solar ovens in Kenya. 56.

Bonsu, S (2019) Development by markets: an essay on the continuities of colonial development and racism in Africa. In Johnson, G. Thomas, K. Harrison, A. \& Grier, S (Eds.), Race in the Marketplace, 259-271. https://doi.org/10.1007/9783-030-11711-5_16

Bucciarelli L (2003) Engineering philosophy. Delft University Press, Delft, Netherlands

Center for Independent Research and Energy for Sustainable Environment (2003) Evaluation of solar Cookit project on Kukuma refugee camp. Final report. Ed. J. Owiti. Available at: https://vignette.wikia.nocookie.net/solarcooking/ images/4/41/Kakuma_evaluation_2003-12.pdf/revision/latest? cb=201 00711225312. Retrieved on March 20, 2020.

Costner, S (2018) Engineers are problem solvers/there's math in my art/cooking with STEAM.... School Library Journal, 26.

De Sousa Santos, B (2007) Beyond abyssal thinking: from global lines to ecologies of knowledges. Review (Fernand Braudel Center), 30(1), 45-89. Retrieved March 17, 2020, from www.jstor.org/stable/40241677
Downey G (2005) Are engineers losing control of technology?: From "problem solving" to "problem definition and solution" in engineering education. Chem Eng Res Des 83(A8):1-12

Downey, G., and Lucena J (2006) The engineer as problem definer: how globalization, underrepresentation, and leadership are variations of the same problem. Invited Distinguished Lecture, American Society of Engineering Education annual conference. Chicago, IL., 2006),

Earl of Durham (1839) Report on the affairs of British North America. Ottawa.

Ferguson, J (1994) The anti-politics machine: "development," depoliticization, and bureaucratic power in Lesotho. University of Minnesota Press.

Gainsburg J, Rodriguez-Lluesma C, Bailey D (2010) A "knowledge profile" of an engineering occupation: Temporal patterns in the use of engineering knowledge. Eng Stud 2(3):197-219 https://doi.org/10.1080/19378629.2010.519773

Gilley, B (2017) The case for colonialism. Third World Quarterly, 1-17. https://doi. org/10.1080/01436597.2017.1369037

Gudynas E (2011) Buen Vivir: today's tomorrow. Development 4(4):441-447

Hanna, L., \& McArdle, P (2016) Solar cooker project best practices manual. Solar Cooker Project of Jewish World Watch. https://www.jww.org/wp-content/ uploads/2016/12/Solar_Cooker_Project_Best_Practices_Manual.pdf

Horner, C. and Hulme, D (2019) From international to global development: new geographies of 21st century development. Development and Change, International Institute of Social Studies, vol. 50(2): 347-378, March.

Jorgensen, K., Raa, J., Saetersdal, G., Williams, J., Broch-Due, V., \& Storas, F. (1980). Aid to fisheries at Lake Turkana - evaluations and recommendations: report by an Advisory Group Appointed by NORAD September 1980. [Report]. NORAD. https://www.oceandocs.org/handle/1834/7251

Kaburu G, James D, Mortimer K (2019) Social determinants and uptake of solar cooking projects- Kakuma Refugee Camp In Kenya. Journal of Poverty, Investment and Development 4(1):1-20

Kapur M (2008) Productive failure. Cogn Instr 26:379-424

Kapur M (2010) Productive failure in mathematical problem solving. Instr Sci 38 $523-550$

Kapur, M. (2014). Productive failure in learning math. Cogn Sci 38 (2014): 1008 1022

Kapur M (2016) Examining productive failure, productive success, unproductive failure, and unproductive success in learning. Educ Psychol 51(2):289-299

Koen B (2003) Discussion of the method: conducting the engineer's approach to problem solving. Oxford University Press, New York

Kothari U, Minogue M (2002) Critical perspectives on development: an introduction. Palgrave, New York

Lucena J, Schneider J, Leydens J (2010) Engineering and sustainable community development. Morgan and Claypool, San Rafael, CA

MacClancy J (2014) Solar cooking: why is it not yet global? Food. Cult Soc 17(2): 301-318 https://doi.org/10.2752/175174414X13871910532060

Martijn Lak (2015) Paul Kennedy, Engineers of victory. The problem solvers who turned the tide in the Second World War. Tijdschrift Voor Sociale En Economische Geschiedenis, 1, 103. https://0-doi-org.mercury.concordia.ca/1 $0.18352 /$ tseg.37

Mazzurco, A. and Daniel, S (2020) Socio-technical thinking of students and practitioners in the context of humanitarian engineering. Journal of Engineering Education, 26.

McArdle, P. (2016) Refugee camps and solar cookers. https://vignette.wikia. nocookie.net/solarcooking/images/e/e3/Refugee_camps_and_solar_ cookers_-_Patricia_McArdle_-_July_2016.pdf/revision/latest?cb=201609221 91259

Mitcham, C. \& Munoz, D (2010) Humanitarian engineering. Morgan and Claypool Publishers.

Munck, R. (2019) Work and capitalist globalization: beyond dualist reason. Review of Radical Political Economics, 0486613418822044. https://doi.org/10.1177/ 0486613418822044

Naseem, M., and Arshad-Ayaz, A (2016) What kind of pedagogy do we need to teach about extremism and terror? Journal of Contemporary Issues in Education. Vol. 11, No. 1, Spring. pp. 6-18.

National Academy of Engineering (2004) The engineer of 2020: visions of engineering in the new century, National Academies Press, Washington, viewed 28 March 2020.

Norwegian Agency for Development Cooperation (2014, August 29) Kenya. NoradDev. https://norad.no/en/front/countries/africa/kenya/

Okech, A. \& Musindarwez, D. (2019). Building Transnational Feminist Alliances: Reflections on the Post-2015 Development Agenda. Contexto Internacional. 41. 255-273. 10.1590/s0102-8529.2019410200002. 
Robinson-Pant A (2001) Development as discourse: what relevance to education? Compare: A Journal of Comparative and International Education 31(3):311328. https://doi.org/10.1080/03057920120098464

Rogers, B., Henderson, M., \& Pugliese, M (2010) The Twig Light: affordable, sustainable lighting for villagers in rural Ghana. Venture Well. Open, San Francisco. https://pdfs.semanticscholar.org/6bcb/827de4075be36c2bae1066 0b4a31f7c234d3.pdf

Schmidt R, Bjork R (1992) New conceptualizations of practice: common principles in three paradigms suggest new concepts for training. Psychol Sci 3:207-217

Shiva, V. (1993). Monocultures of the Mind: Biodiversity, Biotechnology and Agriculture, Zed Press, New Delhi.

Shiva, V (2009) The practice of earth democracy. development dialogue: what next, the case for pluralism No 52, vol. 2: 79-104.

Tharoor S (2016) Inglorious empire: what the British did to India. Hurst \& Co., London

Veltmeyer, H. (ed.) (2011) Bringing history back in. In The critical development studies handbook: Tools for change (pp. 13-33).

Watson C., Migot Adholla, S., Revold, J., Karuga Kihiu, J., Broch Due, V., Gikonyo, P., Bjordal, E., \& Okubu, J (1985) Evaluation Report on The Lake Turkana Fisheries Development Project. (Evaluations 5.85; Evaluation Report). https://norad.no/ en/toolspublications/publications/2010/lake-turkana-fisheries-developmentproject\%2D\%2D/

Wetmore, J. (2012) The Value of the Social Sciences for Maximizing the Public Benefits of Engineering. 42(3), 72.

\section{Publisher's Note}

Springer Nature remains neutral with regard to jurisdictional claims in published maps and institutional affiliations.

\section{Submit your manuscript to a SpringerOpen ${ }^{\circ}$ journal and benefit from:}

- Convenient online submission

- Rigorous peer review

- Open access: articles freely available online

High visibility within the field

- Retaining the copyright to your article

Submit your next manuscript at $\boldsymbol{\nabla}$ springeropen.com 